\title{
A Retrospective, Case-Note Survey of Type 2 Diabetes Patients Prescribed Incretin-Based Therapies in Clinical Practice
}

\author{
Marc Evans • Phil McEwan • Richard O'Shea • \\ Lindsay George
}

To view enhanced content go to www.diabetestherapy-open.com Received: October 15, 2012 / Published online: December 8, 2012

(C) The Author(s) 2012. This article is published with open access at Springerlink.com

\begin{abstract}
Introduction: While incretin-based therapies have been compared in clinical trials, data comparing their relative efficacy in clinical practice remain limited, particularly when

Data from this audit have previously been presented as a poster at the American Diabetes Association's 72nd scientific sessions, June 8-12, 2012, Philadelphia, PA (poster 1116-P; Evans M, et al. Diabetes. 2012;61(Suppl. 1):A288). Data have also been accepted for presentation as an abstract at the 9th International Diabetes Federation Western Pacific Region Congress, November 24-27, 2012, Kyoto, Japan; and at the 1st American Diabetes Association Middle East Congress, December 4-6, 2012, Dubai, UAE.
\end{abstract}

M. Evans $(\varangle) \cdot$ L. George

University Hospital Llandough, Penlan Road, Llandough, Penarth, South Glamorgan, UK

e-mail: marc.evans2@ntlworld.com

P. McEwan

Swansea University, Singleton Park, Swansea, UK

R. O'Shea

University of Wales College of Medicine, Heath

Park, Cardiff Heath Park, Cardiff, UK

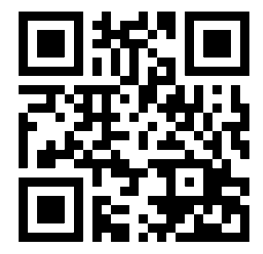

Enhanced content for this article is

available on the journal web site:

www.diabetestherapy-open.com prescribed according to clinical guidelines. This study assessed the clinical and costeffectiveness of, and patient preference for, incretin-based therapies initiated according to the National Institute for Health and Clinical Excellence (NICE) recommendations in UK clinical practice.

Methods: In a retrospective chart audit, anonymized data were collected for patients receiving incretin-based therapy according to NICE recommendations in clinical practice in Wales, UK. Parameters assessed included glycated hemoglobin $\left(\mathrm{HbA}_{1 \mathrm{c}}\right)$, weight, achievement of NICE treatment continuation criteria, adverse events, treatment discontinuation, and drug cost-effectiveness based on observed treatment effects. Treatment preference for a dipeptidyl peptidase-4 inhibitor (DPP-4i) or glucagon-like peptide-1 receptor agonist (GLP-1RA) was assessed prospectively.

Results: Patients $(1,114)$ were followed-up for a median of 48 weeks (256 received liraglutide, 148 received exenatide twice daily, and 710 received a DPP-4i). Liraglutide reduced $\mathrm{HbA}_{1 \mathrm{c}}$ significantly more versus exenatide or DPP-4i (both $P<0.05$ ). Weight changes were similar for GLP-1RAs but significantly greater vs. DPP-4is 
(both $P<0.05$ ). NICE treatment continuation criteria were met by $32 \%$ and $24 \%$ of liraglutide $1.2 \mathrm{mg}$ - and exenatide-treated patients $(\geq 1 \%$ $\mathrm{HbA}_{1 \mathrm{c}}$ reduction, $\geq 3 \%$ weight loss), and $61 \%$ of DPP-4i-treated patients $\left(\geq 0.5 \% \quad \mathrm{HbA}_{1 \mathrm{c}}\right.$ reduction). Life-years gained per patient were $0.12,0.08$, and 0.07, and costs per qualityadjusted life-year were $£ 16,505, £ 16,648$, and $£ 20,661$ for liraglutide, exenatide, and DPP-4is, respectively. More patients (62.5\%) preferred the GLP-1RA profile, with these patients having higher baseline body mass index score and $\mathrm{HbA}_{1 \mathrm{c}}$ values, and longer diabetes duration than those preferring the DPP-4i profile.

Conclusion: When prescribed according to NICE recommendations, incretin-based therapies are both clinically and cost-effective options, with liraglutide providing greatest $\mathrm{HbA}_{1 \mathrm{c}}$ reductions. Greater body weight reductions occur with GLP1RAs compared with DPP-4is. Patients with higher baseline $\mathrm{HbA}_{1 \mathrm{c}}$ and longer diabetes duration prefer a GLP-1RA profile versus a DPP-4i.

Keywords: Clinical effectiveness; Costeffectiveness; Incretin therapies; Routine clinical practice; Type 2 diabetes

\section{INTRODUCTION}

When metformin and lifestyle changes become insufficient in treating type 2 diabetes mellitus (T2DM), advancing treatment with traditional therapies (sulfonylureas [SUs], thiazolidinediones [TZDs], and insulin) can be complicated by weight gain and hypoglycemia [1]. In clinical trials, adding incretin-based therapies to existing oral therapy has been shown to improve glycemic control without weight gain and with low hypoglycemia incidence (especially when used without SUs) [2-6]. Head-to-head studies of up to 12 months' duration suggest that glucagon-like peptide-1 receptor agonists (GLP-1RAs) have greater glycemic efficacy and result in significantly more weight loss compared with the dipeptidyl peptidase-4 inhibitor (DPP-4i) sitagliptin [7-10]. Furthermore, patientreported data suggest a greater improvement in treatment satisfaction with liraglutide $1.8 \mathrm{mg}$ versus sitagliptin; treatment satisfaction data were similar for liraglutide $1.2 \mathrm{mg}$ versus sitagliptin [11].

The National Institute of Health and Clinical Excellence (NICE) recommendations for incretin-based therapies reflect their key benefits, endorsing use (in combination with one or two oral therapies) when hypoglycemia and/or weight gain are a particular concern [12-14]. In general, DPP-4is recommended earlier in the treatment pathway, with less stringent treatment continuation criteria compared with GLP-1RAs. While incretinbased therapies have been compared in clinical trials [7-10, 15, 16], Data comparing their relative efficacy in clinical practice remains limited, particularly when prescribed according to clinical guidelines.

With these issues in mind, using primary care data, a retrospective chart audit was conducted to compare the clinical and costeffectiveness of liraglutide, exenatide twice daily (b.i.d.), and DPP-4is when initiated according to current NICE recommendations. Once-weekly exenatide was not included as it was unavailable for routine use at the time of this study. As NICE also advocates patient involvement in therapy choice and treatment goals [17], the audit was complemented by a prospective patient preference survey in patients considered appropriate for treatment intensification with incretin-based therapy. The survey's aim was to compare preferences for GLP-1RAs with DPP-4is. Based on clinical trial 
data, it was hypothesized that liraglutide would provide greater glycated hemoglobin $\left(\mathrm{HbA}_{1 \mathrm{c}}\right)$ efficacy compared with DPP-4is and exenatide. As GLP-1RA use can result in weight loss, we also hypothesized that patients with a greater baseline body mass index (BMI) would prefer a drug with a GLP-1RA profile.

\section{PATIENTS AND METHODS}

\section{Retrospective Survey, Patient Selection, Data Collection, and Analyses}

Anonymized data were collected from 15 participating primary care centers in South Wales, UK, for patients with T2DM commencing treatment with a DPP-4i or GLP-1RA between May 2009 and November 2011 in accordance with current NICE recommendations [12, 13]. Data were collected at baseline and 3, 6, 9, and 12 months after incretin-based therapy initiation, and at audit end (November 2011). Extracted outcome data comprised $\mathrm{HbA}_{1 \mathrm{c}}$, weight, blood pressure, total cholesterol, and plasma triglycerides. Data on treatment discontinuation (including reasons for switching) and adverse events (AEs; including symptomatic hypoglycemia or severe hypoglycemia [requiring third-party assistance]) were also collected, where available.

Endpoints were calculated for the intent-totreat population (patients receiving at least one dose of incretin-based therapy). Based on similar efficacy results for DPP-4is in clinical trials [18], patients receiving sitagliptin, saxagliptin, or vildagliptin were pooled into a DPP-4i treatment group. GLP-1RA use was divided into two groups-liraglutide $(1.2 \mathrm{mg}$ and $1.8 \mathrm{mg}$ ) and exenatide BID-due to significant differences in glycemic efficacy reported in a head-to-head clinical trial [15].
For baseline demographics, differences in the mean of continuous and categorical variables were compared using repeated analysis of variance (ANOVA). Changes from baseline to each time point were calculated for each group for $\mathrm{HbA}_{1 \mathrm{c}}$, weight, blood pressure, total cholesterol, and plasma triglyceride at 3, 6, 9, and 12 months, after checking residuals for normality. For patients previously receiving a DPP-4i, changes in $\mathrm{HbA}_{1 \mathrm{c}}$ and weight from baseline were assessed following 12 months of liraglutide or exenatide treatment. Similarly, for patients previously receiving exenatide, the effect of 12-months liraglutide treatment was evaluated. No patients switched from liraglutide to exenatide.

The proportion of patients satisfying the NICE 6-month treatment continuation criteria $\left[12\right.$, 13] for DPP-4is ( $\geq 0.5 \% \mathrm{HbA}_{1 \mathrm{c}}$ reduction) and triple-therapy GLP-1RA use $\left(\geq 1 \% \mathrm{HbA}_{1 \mathrm{c}}\right.$ reduction with $\geq 3 \%$ weight loss) was assessed. When used as dual therapy, liraglutide has different continuation criteria $\left(\geq 1 \% \quad \mathrm{HbA}_{1 \mathrm{c}}\right.$ reduction) but, due to the small numbers of patients receiving this combination in this audit, for the endpoint analysis, the more stringent triple-therapy continuation criteria were applied. The proportion of patients achieving the composite endpoint $\geq 1 \% \mathrm{HbA}_{1 \mathrm{c}}$ reduction coupled with any weight loss was also analyzed. Comparisons between treatment groups were performed for the proportion of patients achieving the composite endpoint, frequency of treatment discontinuation, AEs, and hypoglycemia. Summary statistics were calculated for AEs and discontinuation, and changes in other blood glucose-lowering therapies.

All analyses were performed using SAS $^{\circledR}$ version 9.1 (SAS Institute Inc., Cary, NC, US). $P$-values $<0.05$ were deemed statistically significant. Statistical calculations were 
performed using Minitab $^{\circledR}$ release 14.11 (Minitab Ltd, Coventry, UK).

\section{Cost-Effectiveness}

Based on observed treatment effects versus baseline, the UK Prospective Diabetes Study (UKPDS) 68 risk equations [19] were applied over a 20-year time horizon into the CORE diabetes model to independently calculate the cost-effectiveness of liraglutide, exenatide, and DPP-4is. This time horizon was chosen based on the mean patient age at therapy initiation and was thus considered to represent lifetime exposure. Cost per quality-adjusted life-year (QALY) for patients prescribed a DPP-4i was based on the annualized retail acquisition cost of the most commonly prescribed agent, sitagliptin ( $£ 433.57$ per year) [20]. In addition, due to the different annual acquisition costs for the two liraglutide doses, cost calculations were based solely on patients receiving the $1.2 \mathrm{mg}$ dose ( $£ 954.84$ per year) [20] as the vast majority of patients were prescribed this dose. Standard acquisition costs were used for exenatide b.i.d. (£830.25 per year) [20].

\section{Prospective Survey of Patient Preference}

From August 4, 2011 to November 8, 2011, treatment preference was assessed in a separate group of patients judged by their primary care practitioner (PCP) to require therapy intensification and for whom incretin-based therapy was appropriate according to NICE recommendations. Patients were shown two medication "profiles" by their PCP: one representing a DPP-4i (sitagliptin), the other a GLP-1RA (liraglutide) (Table 1). As the longest head-to-head study was between sitagliptin and liraglutide, data from that study were used for the patient preference questionnaire for route of administration, efficacy, side effects, and treatment satisfaction [7, 8, 11]. Informed consent was obtained and patients were asked which drug they would prefer to be prescribed in addition to their current medication if their blood sugar levels were too high. Subsequent responses were anonymized and results collated.

As in a previous patient preference survey [21], after patients reported their preference, they were asked to rank the importance of the following reasons for their decision: administration method (oral or injection); blood glucose-lowering effect; side-effects (nausea, vomiting, and diarrhea); and other effects (weight loss and blood pressure decrease). Continuous variables were compared using a $t$ test, categorical variables using a $\chi^{2}$ test, and overall patient preference was assessed by logistic regression, controlling for all demographic and patient characteristic variables. All analyses and statistical calculations were performed using SAS and Minitab, as for the retrospective survey.

\section{RESULTS}

\section{Retrospective Survey}

\section{Baseline Characteristics}

In total, 1,114 patients had detailed baseline and follow-up data and were included in the retrospective audit: 256 received liraglutide (1.2 mg once daily (o.d.): 229; $1.8 \mathrm{mg}$ o.d.: 27 ), 148 exenatide $10 \mu$ g b.i.d., and 710 a DPP-4i (sitagliptin $100 \mathrm{mg}$ o.d., $n=425$; vildagliptin $50 \mathrm{mg}$ o.d. or b.i.d., $n=210$; saxagliptin $5 \mathrm{mg}$ o.d., $n=75$ ). The median (range) follow-up for the audit group as a whole was 48 (0.4-119) weeks.

At baseline, patients initiated on liraglutide or exenatide therapy had significantly higher mean baseline $\mathrm{HbA}_{1 \mathrm{c}}$, durations of diabetes, and 


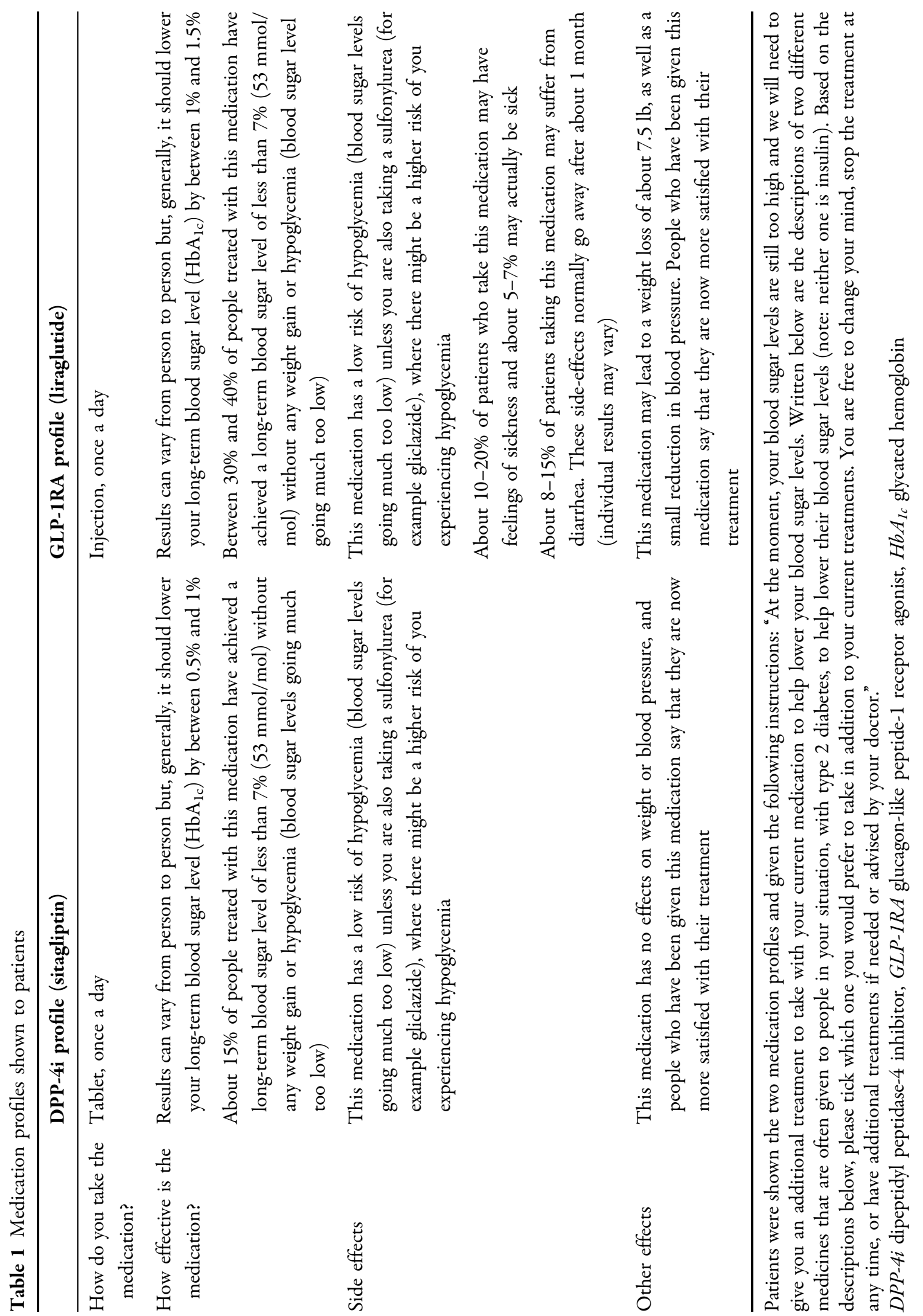


mean body weights compared with patients starting DPP-4is (Table 2). Furthermore, the majority (92\%) of GLP-1RA use was in triple therapy, while over $15 \%$ of DPP-4i use was in dual combination with metformin. Additionally, a significantly greater proportion of patients

Table 2 Baseline characteristics of patients receiving either liraglutide, exenatide, or a DPP-4i

\begin{tabular}{|c|c|c|c|c|}
\hline & \multicolumn{2}{|l|}{ GLP-1RA } & \multirow{2}{*}{$\begin{array}{l}\text { DPP-4i } \\
(n=710)\end{array}$} & \multirow[t]{2}{*}{$P$ value } \\
\hline & $\begin{array}{l}\text { Liraglutide } \\
(n=256)\end{array}$ & $\begin{array}{l}\text { Exenatide } \\
(n=148)\end{array}$ & & \\
\hline Caucasian (\%) & 92.1 & 93.6 & 89.4 & NS \\
\hline Male (\%) & 66.9 & 59.3 & 53.8 & NS \\
\hline Age, years $( \pm S D)$ & $63.5(8.9)$ & $64.1(9.5)$ & $59.5(7.8)$ & NS \\
\hline $\mathrm{HbA}_{1 \mathrm{c}}(\mathrm{mmol} / \mathrm{mol})$ & 81 & 84 & 65 & $<0.05^{*, * *}$ \\
\hline $\mathrm{HbA}_{1 \mathrm{c}}[\%( \pm \mathrm{SD})]$ & $9.6(0.5)$ & $9.8(0.8)$ & $8.1(0.4)$ & \\
\hline Recorded duration of diabetes [years $( \pm S D)$ ] & $11.5(6.6)$ & $12.8(8.2)$ & $6.9(4.1)$ & $<0.05^{*, * *}$ \\
\hline Weight $[\mathrm{kg}( \pm S \mathrm{SD})]$ & $109.7(9.9)$ & $110.6(10.7)$ & $88.9(9.1)$ & $<0.05^{*, * *}$ \\
\hline $\mathrm{BMI}\left[\mathrm{kg} / \mathrm{m}^{2}( \pm \mathrm{SD})\right]$ & $39.5(6.4)$ & $40.2(8.6)$ & $31.1(4.5)$ & $<0.05^{* * * *}$ \\
\hline Blood pressure $[\mathrm{mmHg}( \pm \mathrm{SD})]$ & $156 / 86(11 / 6)$ & $160 / 88(15 / 8)$ & $153 / 79(10 / 6)$ & NS \\
\hline Total cholesterol $[\mathrm{mmol} / \mathrm{L}( \pm \mathrm{SD})]$ & $4.5(0.4)$ & $4.1(0.6)$ & $4.6(0.7)$ & NS \\
\hline Plasma triglycerides $[\mathrm{mmol} / \mathrm{L}( \pm \mathrm{SD})]$ & $2.9(1.4)$ & $2.8(1.9)$ & $2.6(1.8)$ & NS \\
\hline \multicolumn{5}{|l|}{ Previous oral therapy } \\
\hline Metformin monotherapy (\%) & 5.5 & 2.7 & 15.8 & $<0.05^{*, * *}$ \\
\hline Metformin/SU combination therapy (\%) & 79.5 & 78.9 & 60.1 & $<0.05^{*, * *}$ \\
\hline $\begin{array}{l}\text { Metformin and TZD combination } \\
\text { therapy }(\%)\end{array}$ & 12.2 & 13.5 & 16.9 & NS \\
\hline SU monotherapy (\%) & 3.2 & 3.9 & 4.1 & NS \\
\hline TZD monotherapy (\%) & 2.6 & 3.7 & 3.1 & NS \\
\hline \multicolumn{5}{|l|}{ Previous incretin-based therapy } \\
\hline DPP-4i (\%) & 21.1 & 6.8 & N/A & $<0.05^{* * *}$ \\
\hline Exenatide (\%) & 23.5 & $\mathrm{~N} / \mathrm{A}$ & $\mathrm{N} / \mathrm{A}$ & NC \\
\hline Lipid-lowering therapy (\%) & 91.6 & 93.4 & 91.9 & NS \\
\hline Antihypertensive therapy (\%) & 88.9 & 86.9 & 85.7 & NS \\
\hline
\end{tabular}

Data are expressed as mean (SD), unless otherwise stated

No patients had previously been treated with liraglutide

${ }^{*} P<0.05$ liraglutide versus DPP-4i, ${ }^{* *} P<0.05$ exenatide versus DPP-4i, ${ }^{* * *} P<0.05$ liraglutide versus exenatide $B M I$ body mass index, $D P P-4 i$ dipeptidyl peptidase-4 inhibitor, GLP-1RA glucagon-like peptide-1 receptor agonist, $H b A_{1 c}$ glycated hemoglobin, $N / A$ not applicable, $N S$ not significant, $N C$ not calculated, $S D$ standard deviation, $S U$ sulfonylurea, TZD thiazolidinedione 
starting with liraglutide were receiving a DPP-4i at baseline, compared with those starting with exenatide $(21.1$ vs. $6.8 \% ; P<0.05) ;$ DPP-4i therapy was discontinued in $97 \%$ and $98 \%$ of patients starting liraglutide and exenatide, respectively.

\section{Efficacy}

Significant reductions in $\mathrm{HbA}_{1 \mathrm{c}}$ from baseline to audit end were apparent in all three treatment groups (all $P<0.05$ ) (Fig. 1). The change in mean $\mathrm{HbA}_{1 \mathrm{c}}$ was significantly greater for liraglutide (1.2 and $1.8 \mathrm{mg}$ ) than exenatide or DPP-4is (both $P<0.05$ ), but not for exenatide versus DPP-4i (Fig. 1). Significant reductions in weight from baseline to audit end were observed for patients receiving a GLP-1RA (Fig. 2), with 3.1 and $2.1 \mathrm{~kg}$ greater weight reduction seen for liraglutide- and exenatidetreated subjects, respectively, versus those prescribed a DPP-4i. Mean $\mathrm{HbA}_{1 \mathrm{c}}$ or weight at 12 months was not statistically different to the 3-, 6-, and 9-month measurements for each group (Table 3). Considering only those receiving liraglutide $1.8 \mathrm{mg}(n=27)$, the mean (standard deviation [SD]) $\mathrm{HbA}_{1 \mathrm{c}}$ and body weight reductions from baseline were $1.28 \%$ $( \pm 0.35)$ and $4.1 \mathrm{~kg}( \pm 7.2)$, respectively. Twelve liraglutide-treated subjects, 32 exenatidetreated subjects, and 25 DPP-4i-treated subjects either failed to complete 3 months of therapy or had no available follow-up data; tolerability issues were the most commonly recorded reason for therapy discontinuation over this time frame ( $n=9$ [liraglutide]; $n=27$ [exenatide], and $n=9$ [DPP-4i]).

Patients previously treated with a DPP-4i switched to GLP-1RA following inadequate glucose reduction. In these patients, reductions in $\mathrm{HbA}_{1 \mathrm{c}}$ and weight from baseline were apparent following 12-month liraglutide

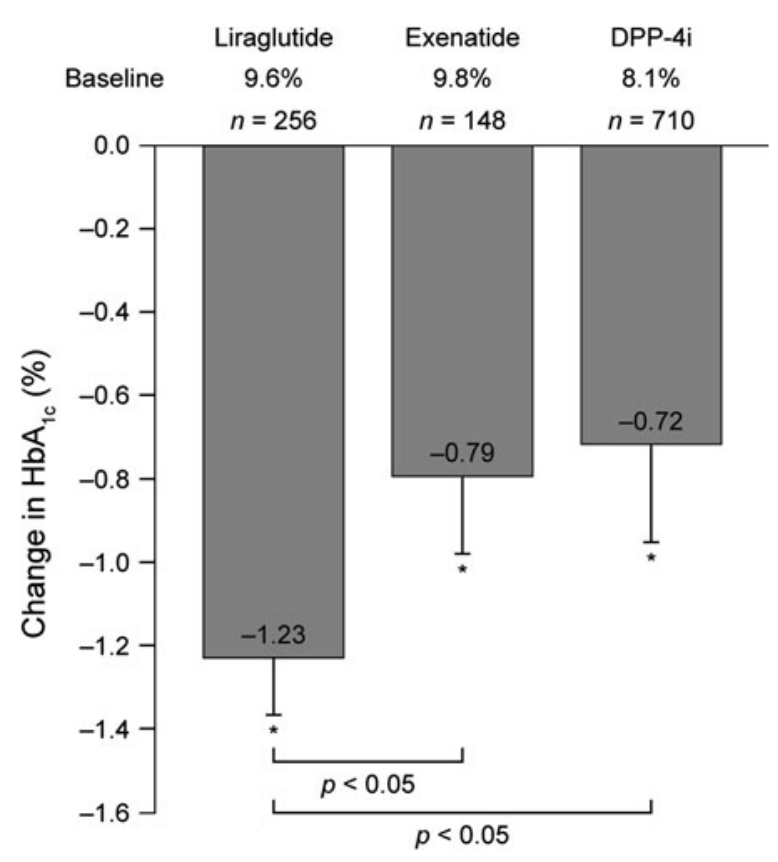

Fig. 1 Mean (SD) reduction in glycated hemoglobin $\left(\mathrm{HbA}_{1 \mathrm{c}}\right)$ from baseline to end of audit. ${ }^{*} P<0.05$ versus baseline. $D P P-4 i$ dipeptidyl peptidase- 4 inhibitor, $S D$ standard deviation

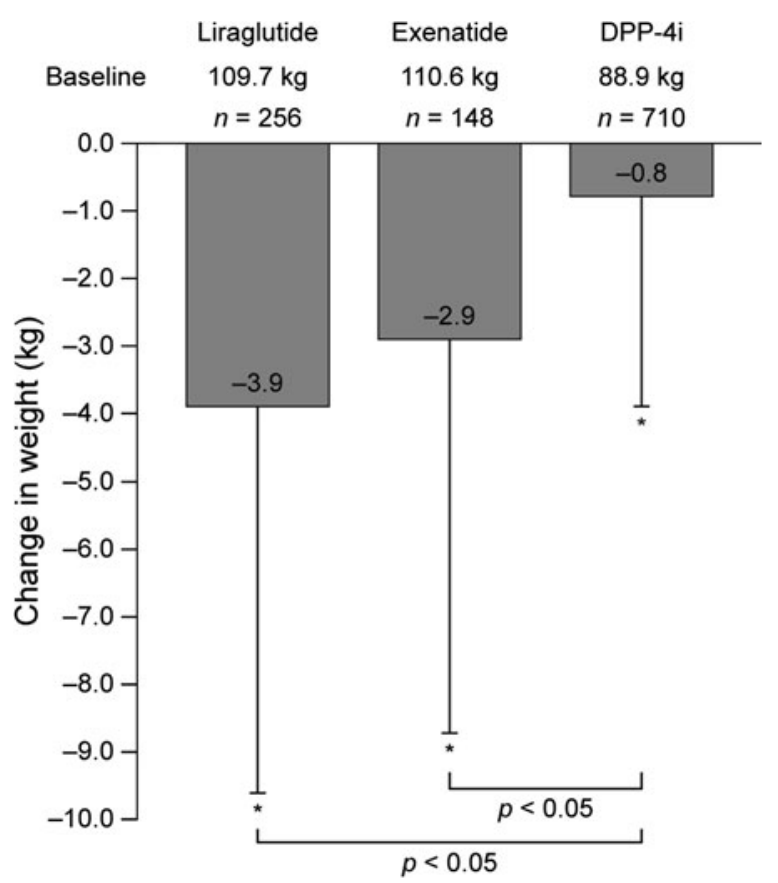

Fig. 2 Mean (SD) reduction in weight from baseline to end of audit. ${ }^{*} P<0.05$ versus baseline. DPP-4i dipeptidyl peptidase- 4 inhibitor, $S D$ standard deviation 
Table 3 Change from baseline in recorded parameters at 3, 6, 9, and 12 months, and at the end of audit

\begin{tabular}{|c|c|c|c|c|c|}
\hline \multirow[t]{2}{*}{ Liraglutide $(1.2$ or $1.8 \mathrm{mg})$} & \multicolumn{5}{|c|}{ Time since initiation of incretin treatment (months) } \\
\hline & $\begin{array}{l}3 \\
n=244\end{array}$ & $\begin{array}{l}6 \\
n=238\end{array}$ & $\begin{array}{l}9 \\
n=209\end{array}$ & $\begin{array}{l}12 \\
n=181\end{array}$ & $\begin{array}{l}\text { Audit end }^{a} \\
n=129\end{array}$ \\
\hline $\mathrm{HbA}_{1 \mathrm{c}}[\%( \pm \mathrm{SD})]$ & $-1.29(0.2)^{* * * *}$ & $-1.21(0.2)^{* * * *}$ & $-1.19(0.1)^{* * * *}$ & $-1.15(0.1)^{* * * *}$ & $-1.22(0.1)^{*, * *}$ \\
\hline Body weight $[\mathrm{kg}( \pm \mathrm{SD})]$ & $-4.4(4.9)^{* *}$ & $-2.9(5.7)$ & $-3.6(5.8)^{* *}$ & $-3.5(6.1)^{* *}$ & $-3.3(5.9)^{* *}$ \\
\hline Blood pressure $[\mathrm{mmHg}( \pm \mathrm{SD})]$ & $-2.8 / 1.1(5.5 / 4.2)$ & $-2.4 / 0.9(4.1 / 3.5)$ & $-2.6 / 1.1(4.1 / 4.2)$ & $-2.2 / 1.1(3.5 / 4.7)$ & $-1.5 / 1.9(5.5 / 3.9)$ \\
\hline Total cholesterol $[\mathrm{mmol} / \mathrm{L}( \pm \mathrm{SD})]$ & $-0.3(0.5)$ & $-0.2(0.4)$ & $+0.1(1.5)$ & $-0.2(0.3)$ & $+0.1(0.3)$ \\
\hline Plasma triglycerides $[\mathrm{mmol} / \mathrm{L}( \pm \mathrm{SD})]$ & $-0.4(0.6)$ & $-0.5(0.8)$ & $-0.4(0.9)$ & $-0.2(0.6)$ & $-0.3(0.8)$ \\
\hline$\%$ Achieving NICE criteria $^{\mathrm{b}}$ & 35 & 32 & 31 & 29 & 28 \\
\hline \multirow[t]{2}{*}{ Exenatide } & \multicolumn{5}{|c|}{ Time since initiation of incretin treatment (months) } \\
\hline & $\begin{array}{l}3 \\
n=116\end{array}$ & $\begin{array}{l}6 \\
n=101\end{array}$ & $\begin{array}{l}9 \\
n=96\end{array}$ & $\begin{array}{l}12 \\
n=92\end{array}$ & $\begin{array}{l}\text { Audit end } \\
n=66\end{array}$ \\
\hline $\mathrm{HbA}_{1 \mathrm{c}}[\%( \pm \mathrm{SD})]$ & $-0.8(0.19)$ & $-0.72(0.15)$ & $-0.69(0.36)$ & $-0.75(0.22)$ & $-0.71(0.31)$ \\
\hline Body weight $[\mathrm{kg}( \pm \mathrm{SD})]$ & $-3.1(4.8)$ & $-2.7(5.7)^{* * *}$ & $-2.9(6.2)^{* * *}$ & $-3.1(6.9)^{* * *}$ & $-2.5(5.9)^{* * *}$ \\
\hline Blood pressure $[\mathrm{mmHg}( \pm \mathrm{SD})]$ & $-2.1 / 1.3(4.4 / 2.5)$ & $-1.5 / 2.1(5.5 / 5.9)$ & $-2.2 / 2.6(4.8 / 3.9)$ & $-1.9 / 1.7(4.1 / 4.9)$ & $-2.1 / 1.1(4.4 / 3.7)$ \\
\hline Total cholesterol, mmol/L ( $\pm \mathrm{SD})$ & $-0.2(0.2)$ & $+0.2(0.4)$ & $-0.3(0.2)$ & $-0.1(0.2)$ & $+0.1(0.3)$ \\
\hline Plasma triglycerides, mmol/L $( \pm \mathrm{SD})$ & $-0.6(0.6)$ & $-0.5(0.4)$ & $-0.3(0.7)$ & $-0.3(0.8)$ & $-0.2(0.8)$ \\
\hline \% Achieving NICE criteria & 27 & 24 & 26 & 25 & 21 \\
\hline \multirow[t]{2}{*}{ DPP-4i } & \multicolumn{5}{|c|}{ Time since initiation of incretin treatment (months) } \\
\hline & $\begin{array}{l}3 \\
n=685\end{array}$ & $\begin{array}{l}6 \\
n=551\end{array}$ & $\begin{array}{l}9 \\
n=471\end{array}$ & $\begin{array}{l}12 \\
n=301\end{array}$ & $\begin{array}{l}\text { Audit end }^{a} \\
n=266\end{array}$ \\
\hline $\mathrm{HbA}_{1 \mathrm{c}}[\%( \pm \mathrm{SD})]$ & $-0.79(0.21)$ & $-0.69(0.15)$ & $-0.71(0.14)$ & $-0.74(0.11)$ & $-0.66(0.19)$ \\
\hline Body weight $[\mathrm{kg}( \pm \mathrm{SD})]$ & $-0.9(2.1)$ & $-0.5(1.9)$ & $-1.1(0.4)$ & $-0.6(0.9)$ & $-0.7(0.5)$ \\
\hline Blood pressure $[\mathrm{mmHg}( \pm \mathrm{SD})]$ & $+1.1 / 0.9(3.5 / 2.9)$ & $-1.3 / 1.7(4.4 / 3.1)$ & $+0.9 / 2.1(5.5 / 3.7)$ & $-1.5 / 1.1 /(5.5 / 3.9)$ & $-1.1 / 1.9(4.5 / 3.9)$ \\
\hline Total cholesterol $[\mathrm{mmol} / \mathrm{L}( \pm \mathrm{SD})]$ & $-0.1(0.4)$ & $-0.1(0.5)$ & $-0.3(0.4)$ & $-0.1(0.6)$ & $-0.2(0.4)$ \\
\hline Plasma triglycerides $[\mathrm{mmol} / \mathrm{L}( \pm \mathrm{SD})]$ & $-0.2(0.2)$ & $-0.4(0.9)$ & $-0.2(0.4)$ & $-0.3(0.4)$ & $-0.3(0.3)$ \\
\hline \% Achieving NICE criteria & 59 & 61 & 52 & 54 & 57 \\
\hline
\end{tabular}

Data are expressed as mean $( \pm \mathrm{SD})$, unless otherwise stated

NICE continuation criteria for GLP-1RA therapy: $\geq 1 \%$ reduction in $\mathrm{HbA}_{1 \mathrm{c}}$ and $\geq 3 \%$ body weight loss

NICE continuation criteria for DPP-4i therapy: $\geq 0.5 \%$ reduction in $\mathrm{HbA}_{1 \mathrm{c}}$

$D P P-4 i$ dipeptidyl peptidase-4 inhibitor, GLP-IRA glucagon-like peptide-1 receptor agonist, $H b A_{1 c}$ glycated hemoglobin, NICE National Institute for Health and Clinical Excellence, $S D$ standard deviation

${ }^{*} P<0.05$ liraglutide versus exenatide; ${ }^{* *} P<0.05$ liraglutide versus DPP-4i; ${ }^{* *} P<0.05$ exenatide versus DPP-4i

${ }^{a}$ For patients with 12 -month data

${ }^{b}$ Only for patients receiving liraglutide $1.2 \mathrm{mg}$

$(1.2 \mathrm{mg} \quad$ or $\quad 1.8 \mathrm{mg}) \quad(n=54) \quad(-0.9 \pm 0.6 \%$ and $-2.5 \pm 1.8 \mathrm{~kg}) \quad$ or exenatide $(n=12)$ $(-0.7 \% \pm 0.9 \%$ and $-2.3 \mathrm{~kg} \pm 2.1 \mathrm{~kg})$ treatment; the changes were statistically significant with liraglutide (both $P<0.05$ vs. baseline) but not exenatide. For previous exenatide-treated patients, the most common reasons for conversion to liraglutide therapy were tolerability problems $(62.6 \%)$ and insufficient $\mathrm{HbA}_{1 \mathrm{c}}$ reduction $(28.4 \%)$, with a mean $( \pm \mathrm{SD})$ exposure to exenatide of $8.7( \pm 6.6)$ weeks. Following 12-month liraglutide treatment, significant $\mathrm{HbA}_{1 \mathrm{c}}(-0.8 \% \pm 0.3 \%)$ and weight $(-2.1 \mathrm{~kg} \pm 3.1 \mathrm{~kg})$ reductions were observed (both $P<0.05$ ).

The proportions of patients achieving the NICE 6-month treatment continuation criteria for GLP-1RAs with liraglutide $1.2 \mathrm{mg}$ and exenatide were $32 \%$ and $24 \%$, respectively. For DPP-4is, $61 \%$ of patients achieved the less stringent criteria at 6 months. The composite endpoint of $\geq 1 \% \mathrm{HbA}_{1 \mathrm{c}}$ reduction with any weight loss was achieved by $60 \%, 48 \%$, and $14 \%$ of patients treated with liraglutide 
(1.2 $\mathrm{mg}$ and $1.8 \mathrm{mg}$ ), exenatide, or a DPP-4i, respectively.

\section{Treatment Discontinuation and AEs}

SU and TZD discontinuation was similar for both GLP-1RA- and DPP-4i-treated patients (liraglutide group: $6.9 \%$ and $7.9 \%$; exenatide group: $8.6 \%$ and $10.9 \%$; DPP-4i group; $7.2 \%$ and $12.1 \%$ ). Insufficient $\mathrm{HbA}_{1 \mathrm{c}}$ reduction was the most frequent reason for DPP-4i discontinuation (83\%), while tolerability problems $(22 \%$ and $42 \%$ ) and insufficient $\mathrm{HbA}_{1 \mathrm{c}}$-lowering effects (27\% and 29\%) were the smost commonly recorded reasons for liraglutide and exenatide discontinuation, respectively.

AEs were more common in patients taking exenatide and liraglutide (39\% and 29\%, respectively) than DPP-4is (9.6\%). The most commonly recorded AEs with liraglutide (26.5\%) and exenatide (33.1\%) were gastrointestinal (diarrhea, nausea, vomiting, abdominal pain, constipation, anorexia). The most commonly reported side effects with DPP-4is were diarrhea (3.9\%), headache $(2.1 \%)$, and nausea (1.7\%). No major hypoglycemia was recorded; symptomatic hypoglycemia was recorded in $0.8 \%, 0.9 \%$, and $0.8 \%$ of people taking liraglutide, exenatide, or a DPP-4i, respectively.

\section{Cost-Effectiveness Analyses}

Based on the end-of-audit observations, the calculated life-years gained per patient, compared with baseline, were 0.12, 0.08, and 0.07 for liraglutide, exenatide, and DPP-4i, respectively. The observed costs per QALY versus baseline for patients prescribed liraglutide, exenatide, or DPP-4i were $£ 16,505, £ 16,648$, and $£ 20,661$, respectively.

\section{Prospective Survey of Patient Preference}

A total of 188 patients completed the survey, with a mean $( \pm \mathrm{SD})$ age of 63.9 years $( \pm 5.9)$, body weight $97.5 \mathrm{~kg}( \pm 8.6)$, BMI $36.7 \mathrm{~kg} / \mathrm{m}^{2}$ $( \pm 5.9)$, and $\mathrm{HbA}_{1 \mathrm{c}} 74 \mathrm{mmol} / \mathrm{mol}(8.9 \%)( \pm 1.1)$. Based on medication profiles provided, significantly more patients $(62.5 \%$ vs. $37.5 \%)$ reported a preference for the drug with the GLP1RA profile compared with the DPP-4i profile $(P<0.05)$. The demographics of patients choosing each drug are shown in Table 4. Weight loss was ranked the most important determinant of choice by $61 \%$ of patients choosing the GLP-1RA profile, and mode of administration by $66 \%$ of patients choosing the DPP-4i profile. Logistic regression analysis demonstrated that the likelihood of preferring the drug with the GLP-1RA profile grew with increasing BMI (odds ratio [OR] 1.54; 95\% confidence interval [CI] 1.22-1.69), duration of diabetes (OR 1.32; 95\% CI 1.12-1.99), and $\mathrm{HbA}_{1 \mathrm{c}}$ level (OR 1.09; 95\% CI 1.04-1.29).

\section{DISCUSSION}

This retrospective UK case-note survey examined outcomes of therapy with GLP-1RAs (reported separately for liraglutide and exenatide) and DPP-4is (pooled for sitagliptin, vildagliptin, and saxagliptin) in routine practice. As treatments were initiated according to NICE recommendations [12, 13], patients prescribed GLP-1RAs had longer disease duration and higher baseline $\mathrm{HbA}_{1 \mathrm{c}}$ and BMIs compared with patients prescribed DPP-4is. In this context, liraglutide provided a significantly greater mean reduction in $\mathrm{HbA}_{1 \mathrm{c}}$ versus DPP-4is or exenatide; reduction in $\mathrm{HbA}_{1 \mathrm{c}}$ was similar with exenatide and DPP-4is. Furthermore, in keeping with current NICE recommendations 
Table 4 Distribution and clinical profile of respondents to patient preference questionnaire

\begin{tabular}{|c|c|c|c|}
\hline & $\begin{array}{l}\text { DPP-4i } \\
\text { profile } \\
\text { (sitagliptin) }\end{array}$ & $\begin{array}{l}\text { GLP-1RA } \\
\text { profile } \\
\text { (liraglutide) }\end{array}$ & $\begin{array}{l}P \text { - } \\
\text { value }\end{array}$ \\
\hline$n[\%( \pm S D)]$ & $70(37.5)$ & $118(62.5)$ & $<0.05$ \\
\hline Age [years $( \pm S D)]$ & $59.5(5.1)$ & $62.6(6.1)$ & $\mathrm{N} / \mathrm{A}$ \\
\hline Male/female (\%) & $54 / 46$ & $59 / 41$ & NS \\
\hline $\begin{array}{l}\text { Body weight }[\mathrm{kg} \\
( \pm \mathrm{SD})]\end{array}$ & $88.9(5.6)$ & $98.5(6.9)$ & $<0.05$ \\
\hline $\begin{array}{l}\text { BMI }\left[\mathrm{kg} / \mathrm{m}^{2}\right. \\
( \pm \mathrm{SD})]\end{array}$ & $31.5(5.5)$ & $37.8(5.9)$ & $<0.05$ \\
\hline $\begin{array}{l}\mathrm{HbA}_{1 \mathrm{c}}(\mathrm{mmol} / \\
\mathrm{mol})\end{array}$ & 70 & 80 & $<0.05$ \\
\hline $\mathrm{HbA}_{1 \mathrm{c}}[\%( \pm \mathrm{SD})]$ & $8.6(0.5)$ & $9.5(0.6)$ & $\mathrm{N} / \mathrm{A}$ \\
\hline $\begin{array}{l}\text { Recorded duration } \\
\text { of diabetes [years } \\
( \pm S D)\end{array}$ & $6.5(3.5)$ & $9.8(3.1)$ & $<0.05$ \\
\hline $\begin{array}{l}\% \text { On background } \\
\text { monotherapy }\end{array}$ & 62.5 & 43.5 & $<0.05$ \\
\hline $\begin{array}{l}\% \text { On background } \\
\text { dual combination } \\
\text { therapy }\end{array}$ & 37.5 & 56.5 & $<0.05$ \\
\hline
\end{tabular}

Data are expressed as mean $( \pm S D)$, unless otherwise stated Comparisons made between people expressing a preference for drug B (GLP-1RA profile) versus drug A (DPP-4i profile)

$B M I$ body mass index, DPP-4i dipeptidyl peptidase- 4 inhibitor, GLP-1RA glucagon-like peptide-1 receptor agonist, $H b A_{1 c}$ glycated hemoglobin, $N / A$ not applicable, $S D$ standard deviation

[13], the vast majority of liraglutide use was with $1.2 \mathrm{mg}$. Mean weight loss was greater with liraglutide compared with DPP-4is and exenatide, and was significantly greater with either GLP-1RA therapy compared with DPP-4is. A total of $32 \%$ and $24 \%$ of patients treated with liraglutide $1.2 \mathrm{mg}$ and exenatide, respectively, met the 6-month NICE treatment continuation criteria for GLP-1RAs, while $61 \%$ of patients treated with a DPP-4i achieved their less stringent criteria [12, 13]. Based on input of the observed clinical effects of the different treatment options as applied of the UKPDS 68 risk equations into the widely accepted CORE diabetes model, liraglutide, exenatide, and DPP-4i therapy were cost-effective treatment options as prescribed at the currently accepted threshold of acceptability of $£ 20,000$ per QALY [12-14], although no direct comparison of the cost-effectiveness profile of these agents could be made from this study since baseline patient demographics were different, coupled with the absence of a randomized approach to therapy initiation. The majority of patients (62.5\%) preferred the GLP-1RA profile, and these patients had greater BMIs, $\mathrm{HbA}_{1 \mathrm{c}}$, and durations of diabetes than patients preferring the DPP- $4 \mathrm{i}$.

While our observed relative efficacies of the incretin-based therapies are generally supported by head-to-head clinical trial data comparing liraglutide, exenatide, and sitagliptin [7, 8, 15], other factors may contribute to our observations. Baseline characteristics differed among treatment groups, with the DPP-4i group having lower $\mathrm{HbA}_{1 \mathrm{c}}$ and BMIs than the GLP-1RA groups. Additionally, more patients in the liraglutide group than the other groups reduced or discontinued SU therapy, which may have contributed to greater absolute weight reduction observed in this cohort.

The relatively poor performance of liraglutide and exenatide in achieving the NICE treatment continuation criteria may reflect their later use in the disease course (baseline $\mathrm{HbA}_{1 \mathrm{c}}$ 81-84 mmol/mol [9.6-9.8\%], duration of diabetes $11.5-12.8$ years) compared with the phase 3 studies $\left(\mathrm{HbA}_{1 \mathrm{c}} 63-70 \mathrm{mmol} /\right.$ mol [7.9-8.6\%], duration of diabetes 5-10 years) upon which the criteria are based [2, 22]. Achieving a 6-month 3\% body weight loss may have been unrealistic for severely obese 
individuals in this audit (baseline BMI $\sim 40 \mathrm{~kg} /$ $\mathrm{m}^{2}$ vs. $36 \mathrm{~kg} / \mathrm{m}^{2}$ in phase 3 studies), requiring absolute weight loss beyond that observed in clinical trials $[2,22]$, particularly as these patients may represent a more treatmentresistant population. Therefore, the composite endpoint of $\geq 1 \% \mathrm{HbA}_{1 \mathrm{c}}$ reduction coupled with any weight loss may provide a better indication of incretin-based therapy efficacy in this setting. This endpoint was achieved by $60 \%, 48 \%$, and $14 \%$ of patients treated with liraglutide (both $1.2 \mathrm{mg}$ and $1.8 \mathrm{mg}$ ), exenatide, or a DPP-4i, respectively. Of note, no records of treatment discontinuation were identified as a consequence of NICE recommendations. Thus, although therapy may be initiated broadly in keeping with current NICE guidance, there appears to be poor adherence to therapy discontinuation rules in routine primary care.

Patients previously receiving exenatide achieved a $0.8 \% \quad \mathrm{HbA}_{1 \mathrm{c}}$ reduction from baseline when switched to liraglutide, in excess of the $0.32 \%$ reduction from baseline seen in the clinical trial switching exenatide to liraglutide [23]. However, this may reflect suboptimal previous exenatide therapy, as the majority of these patients $(62.6 \%)$ discontinued exenatide due to tolerability issues. Patients previously receiving DPP-4is demonstrated meaningful reductions in $\mathrm{HbA}_{1 \mathrm{c}}$ and body weight from baseline when switched to exenatide or liraglutide. This likely reflects the higher GLP-1 receptor stimulation provided by GLP-1RA therapy compared with DPP-4is, and emphasizes the success of switching patients from a DPP-4i to a GLP-1RA [24, 25].

Despite widespread use of concomitant SU therapy, symptomatic hypoglycemia was reported by few patients $(<1 \%)$. This may reflect underreporting by both patients and healthcare professionals and may also be related to the high baseline levels of glucose control. Gastrointestinal side effects were the most frequently reported $\mathrm{AE}$ in exenatide(33.1\%) and liraglutide-treated (26.5\%) patients, in line with rates from clinical trials $[22,26]$. However, therapy discontinuation due to gastrointestinal side effects was greater than seen in clinical trials $[6-8,15]$, possibly reflecting the impact of routine practice, as opposed to the clinical trial setting, which often includes highly motivated patients who undergo more monitoring than patients in routine clinical practice.

The health economic observations represent the cost-effectiveness profile of liraglutide, exenatide, and DPP-4is as prescribed in routine clinical practice, and thus may be more noteworthy than similar data derived from trials. However, as this analysis was limited to withintreatment group assessments compared with baseline, and as patients who were prescribed GLP-1RAs were markedly phenotypically different from those prescribed DPP-4is, it is impossible to directly compare the costeffectiveness profiles of the different therapies.

The majority of patients surveyed preferred the GLP-1RA profile (62.5\%) over the DPP-4i profile (37.5\%); however, the phenotypic profile of the survey population may have been a source of potential bias with respect to the observed results. These data are at variance with a previous study [21], and may partly reflect the different patient populations included in each analysis; under a third of patients included in the previous survey had an $\mathrm{HbA}_{1 \mathrm{c}}$ above their individual target at their last doctor's visit. Weight loss was the most common reason for patients choosing the GLP-1RA profile, while mode of administration was important for those choosing the DPP-4i profile. These observations imply that, for patients with more advanced disease and higher baseline body weight, potential clinical effects, particularly relating 
to weight loss, may outweigh barriers presented by an injectable mode of administration. This is supported by treatment satisfaction data from the liraglutide versus sitagliptin phase 3 study [11]. For patients already close to their individual glycemic target, and for whom weight is not a particular concern, the ease of adding an orally administered DPP-4i to existing therapy may, however, be preferable.

While real-world observations such as these provide useful insight into the utility of different therapies in clinical practice, several limitations of the analysis should be considered. Selection bias, the uncontrolled nature of treatment changes, and the absence of strict research protocols and rigorous data capture are some of the inherent limitations. Additionally, the patient preference analysis did not include any validated measure of baseline healthutility state, representing another possibly confounding variable. Finally, for the economic analysis, the acquisition cost of sitagliptin was used for all patients prescribed a DPP-4i, which might affect interpretation of these data since there are small retail acquisition cost differences between the prescribed DPP-4is [20].

\section{CONCLUSION}

In summary, in this retrospective analysis of the clinical and cost-effectiveness of incretinbased therapies initiated according to NICE recommendations, liraglutide provided numerically greater reductions in $\mathrm{HbA}_{1 \mathrm{c}}$ and body weight, compared with exenatide or DPP4is, while liraglutide, exenatide, and DPP-4is appeared to represent cost-effective treatment options as prescribed. Patients with more advanced disease (higher baseline $\mathrm{HbA}_{1 \mathrm{c}}$ and longer diabetes duration) and higher baseline BMIs appeared to prefer a drug with a GLP-1RA profile versus a DPP- $4 \mathrm{i}$. The observations from our analysis demonstrate the utility of liraglutide in routine clinical practice and suggest that clinical trial data appears to translate into therapeutic benefits in routine practice. Further research is, however, required in both clinical trials and routine practice, to evaluate the optimal positioning of the various incretin-based therapies in the T2DM treatment continuum.

\section{ACKNOWLEDGMENTS}

The authors are grateful to Alison Clarke of University Hospital Llandough, Llandough, UK, for assistance with data collection and Dr. David Harvey of Watermeadow Medical, Witney, UK, for writing and editorial assistance, funded by Novo Nordisk. Dr. Marc Evans is the guarantor for this article, and takes responsibility for the integrity of the work as a whole.

Conflict of interest. Dr. Marc Evans has received honoraria and research awards from Novo Nordisk, Sanofi-aventis, Merck Sharp \& Dohme, Novartis, Eli Lilly and GlaxoSmithKline. The remaining authors have no conflicts of interest to declare.

Open Access. This article is distributed under the terms of the Creative Commons Attribution Noncommercial License which permits any noncommercial use, distribution, and reproduction in any medium, provided the original author(s) and the source are credited.

\section{REFERENCES}

1. Inzucchi SE, Bergenstal RM, Buse JB, et al. Management of hyperglycaemia in type 2 diabetes: a patient-centered approach. Position 
statement of the American Diabetes Association (ADA) and the European Association for the Study of Diabetes (EASD). Diabetologia. 2012;55:1577-96.

2. Amori RE, Lau J, Pittas G. Efficacy and safety of incretin therapy in type 2 diabetes. JAMA. 2007; 298:194-206.

3. Victoza ${ }^{\circledR} 6 \mathrm{mg} / \mathrm{ml}$ solution for injection in pre-filled pen (summary of product characteristics). Novo Nordisk Limited; 2012. http://www.medicines.org. uk/emc/medicine/21986/. Accessed 04 Oct 2012.

4. Byetta $^{\circledR} 5$ micrograms solution for injection, prefilled pen. Byetta 10 micrograms solution for injection, prefilled pen (summary of product characteristics). Eli Lilly and Company Limited; 2012. http://www. medicines.org.uk/EMC/medicine/19257/ Accessed 04 Oct 2012.

5. BYDUREON $^{\circledR} 2 \mathrm{mg}$ powder and solvent for prolonged-release suspension for injection (summary of product characteristics). Eli Lilly and Company Limited; 2011. http://www. medicines.org.uk/EMC/medicine/24665/. Accessed 04 Oct 2012.

6. Shyangdan DS, Royle P, Clar C, Sharma P, Waugh NR. Glucagon-like peptide analogues for type 2 diabetes mellitus. Cochrane Database Syst Rev. 2011;5:CD006423.

7. Pratley RE, Nauck M, Bailey T, for the 1860LIRA-DPP-4 Study Group, et al. Liraglutide versus sitagliptin for patients with type 2 diabetes who did not have adequate glycaemic control with metformin: a 26-week, randomised, parallel-group, open-label trial. Lancet. 2010;375:1447-56.

8. Pratley R, Nauck M, Bailey T, 1860-LIRA-DPP-4 Study Group, et al. One year of liraglutide treatment offers sustained and more effective glycaemic control and weight reduction compared with sitagliptin, both in combination with metformin, in patients with type 2 diabetes: a randomised, parallel-group, open-label trial. Int J Clin Pract. 2011;65:397-407.

9. DeFronzo RA, Okerson T, Viswanathan P, Guan X, Holcombe JH, MacConell L. Effects of exenatide versus sitagliptin on postprandial glucose, insulin and glucagon secretion, gastric emptying, and caloric intake: a randomized, cross-over study. Curr Med Res Opin. 2008;24:2943-52.

10. Berg JK, Shenouda SK, Heilmann CR, Gray AL, Holcombe JH. Effects of exenatide twice daily versus sitagliptin on 24-h glucose, glucoregulatory and hormonal measures: a randomized, doubleblind, crossover study. Diabetes Obes Metab. 2011;13:982-9.
11. Davies M, Pratley R, Hammer M, Thomsen AB, Cuddihy R. Liraglutide improves treatment satisfaction in people with Type 2 diabetes compared with sitagliptin, each as an add on to metformin. Diabet Med. 2011;28:333-7.

12. NICE: Liraglutide for the treatment of type 2 diabetes. 2010. http://www.nice.org.uk/nicemedia/ live/13248/51259/51259.pdf. Accessed 14 Jun 2012.

13. NICE. The management of type 2 diabetes. Clinical guideline 87. 2009. http://www.nice.org.uk/nice media/pdf/CG87NICEGuideline.pdf. Accessed 14 Jun 2012.

14. NICE: Exenatide prolonged-release suspension for injection in combination with oral antidiabetic therapy for the treatment of type 2 diabetes. 2012. http://www.nice.org.uk/nicemedia/live/13670/5820 5/58205.pdf. Accessed 14 Jun 2012.

15. Buse JB, Rosenstock J, Sesti G, LEAD-6 Study Group, et al. Liraglutide once a day versus exenatide twice a day for type 2 diabetes: a 26-week randomised, parallel-group, multinational, open-label trial (LEAD-6). Lancet. 2009;374:39-47.

16. Buse JB, Nauck MA, Forst T, et al. Efficacy and safety of exenatide once weekly versus liraglutide in subjects with type 2 diabetes (DURATION-6): a randomised, open-label study. Diabetologia. 2011;54(Suppl. 1):S38. Abstract A75.

17. NICE: Diabetes in adults quality standard. 2011. http://www.nice.org.uk/guidance/qualitystandards/ diabetesinadults/diabetesinadultsqualitystandard.jsp. Accessed 14 Jun 2012.

18. Gerich J. DPP-4 inhibitors: what may be the clinical differentiators? Diabetes Res Clin Pract. 2010;90: 131-40.

19. Clarke PM, Gray AM, Briggs A, et al. A model to estimate the lifetime health outcomes of patients with Type 2 diabetes: the United Kingdom Prospective Diabetes Study (UKPDS) Outcomes Model (UKPDS no. 68). Diabetologia. 2004;47:1747-59.

20. MIMS: http://www.MIMS.co.uk. Accessed 12 Nov 2012.

21. Dibonaventura MD, Wagner JS, Girman CJ, et al. Multinational Internet-based survey of patient preference for newer oral or injectable Type 2 diabetes medication. Patient Prefer Adherence. 2010;4:397-406.

22. Davies MJ, Kela R, Khunti K. Liraglutide: overview of the preclinical and clinical data and its role in the treatment of type 2 diabetes. Diabetes Obes Metab. 2011;13:207-20. 
23. Buse JB, Sesti G, Schmidt WE, Liraglutide Effect Action in Diabetes-6 Study Group, et al. Switching to once-daily liraglutide from twice-daily exenatide further improves glycemic control in patients with type 2 diabetes using oral agents. Diabetes Care. 2010;33:1300-3.

24. Degn KB, Juhl CB, Sturis J, et al. One week's treatment with the long-acting glucagon-like peptide 1 derivative liraglutide (NN2211) markedly improves 24-h glycemia and alpha- and beta-cell function and reduces endogenous glucose release in patients with type 2 diabetes. Diabetes. 2004;53:1187-94.
25. Mari A, Sallas WM, He YL, et al. Vildagliptin, a dipeptidyl peptidase-IV inhibitor, improves model-assessed beta-cell function in patients with type 2 diabetes. J Clin Endocrinol Metab. 2005; 90:4888-94.

26. Madsbad S. Exenatide and liraglutide: different approaches to develop GLP-1 receptor agonists (incretin mimetics)-preclinical and clinical results. Best Pract Res Clin Endocrinol Metab. 2009;23:463-77. 